\title{
Using OCLC WorldCat to Survey Government Publications in a Library's Collection
}

\author{
Linda Zellmer
}

A method to evaluate a library's government information collection using OCLC's WorldCat is described. By searching material type codes for government publications, and limiting the search to an owning library, it is possible to find the number of cataloged government publications in a library's collection. The system can be used to identify the age of government publications in a library, the number of items on a given subject, and find publications on a topic from a specific time period. This method of analysis is especially useful for analyzing government information collections when publications are cataloged into a library's main collection. The search technique can be used to generate statistics on government publication collections which can be used to prepare reports on library collections and materials.

A t some point, every government information librarian wants to learn more about the materials in their collection, including its size and the age range of the materials. The reasons for wanting more information may vary from providing information for library reports to developing displays. For example, government information librarians in academic libraries with separate government publication collections may be asked for information on the number of government publications on a specific topic for a department's accreditation report. While a systems librarian can generate statistics on publications for that department based on call number ranges, they may find it difficult to find materials on that topic in the government publications collection. For example, government publications on agriculture could take the form of a report issued by the U.S. Department of Agriculture or a Congressional hearing or report. Materials on water pollution could be published by a variety of agencies, including the Environmental Protection Agency, bureaus and offices of the Department of the Interior or a Congressional hearing or report. In a library where documents are separated from the main library collection, a librarian may be able to use the local online public access catalog (OPAC) to search for materials on a specific topic in the government publications collection if the OPAC can limit searches by location. However, most online catalogs cannot be used to get statistics on the total number of items in a library by location, because they require a term to be searched before supplying results. In libraries where government publications are intershelved with other library materials, it is especially difficult to gather information on the library's collection of government publications. One resource available to many librarians, WorldCat (FirstSearch) from OCLC, can be used to find information about a library's government publication collection. This article provides information on using OCLC's WorldCat to survey the cataloged government publications in a library. It provides information on searching for government publications, as well as searches for publications by age, topic and format.

\section{Finding Government Publications using WorldCat}

To find government publications available in a library using WorldCat, a search on material type is performed. In a MARC cataloging record, the fixed fields are used to note a variety of information, including whether an item is a government publication and its format. When a government publication is cataloged, catalogers enter a code in the GPub field of the fixed fields of the OCLC record that indicates the type of government publication: i for international intergovernmental publications; f for federal government publications; $\mathbf{s}$ for state government publications; and $\mathbf{1}$ for local government publications. ${ }^{1}$ A complete list of the codes is available in OCLC's Input Standards for 


\section{Using OCLC WorldCat to Survey Government Publications in a Library's Collection}

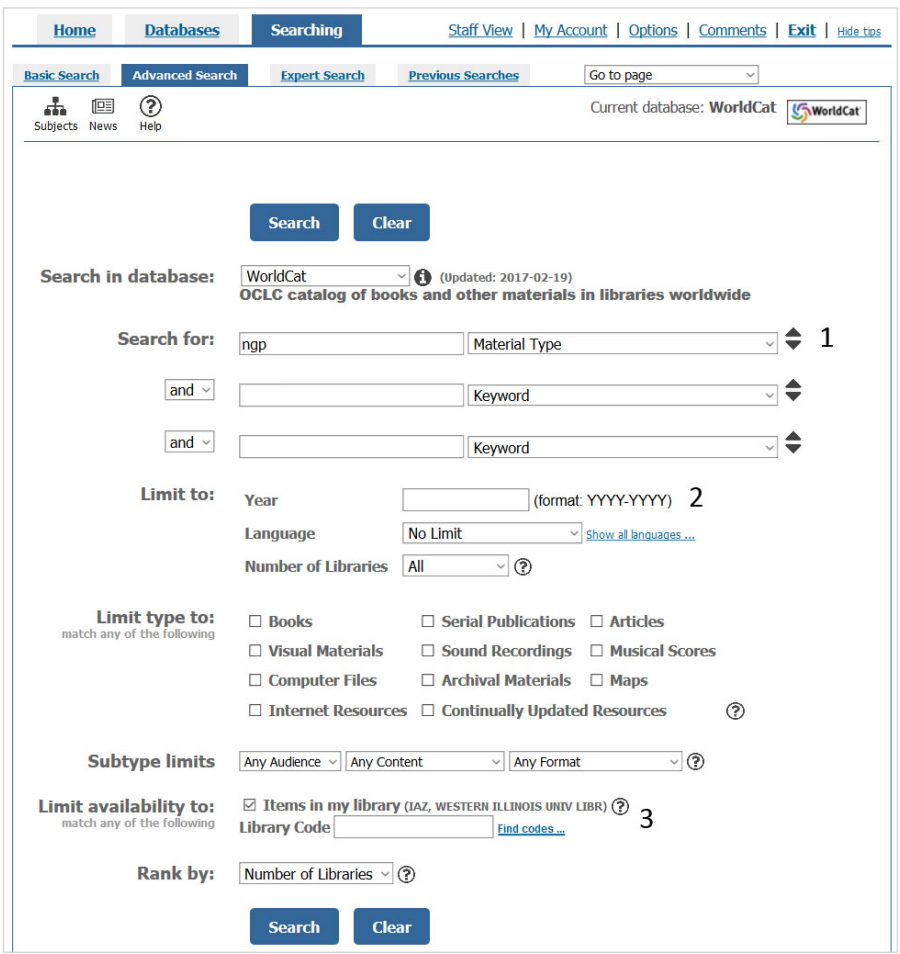

Figure 1. Illustration showing a search for federal government publications in WorldCat advanced search. 1. Enter "ngp" in the Search for: box and use the pull-down to specify Material Type. 2. Enter date if needed. 3. Check the Items in my library box.

Fixed-Field Elements and 006: GPub: Government Publication. ${ }^{2}$ The advanced search system in WorldCat, the public OCLC interface, can be used to find government publications by searching the material type. To use WorldCat advanced search to find government publications, enter the material type code for the type of government publication of interest and use the pull-down menu in the user interface to select "Material Type" (figure 1). ${ }^{3}$ The material type codes for common government publications in WorldCat are:

- gpb—any government publication

- igp-international government publication

- ngp-national government publication

- $\quad$ sgp—state government publication

- $\quad \lg$-local government publication

When searching only for materials in the local collection, check the "Items in my library" box. The WorldCat search results (figure 2) provides information on the number of cataloged national government publications available in the Western Illinois University (WIU) Library, as well as the number of items by format. While the results include microform publications, they are not reported as a separate format. To get information on the number of microforms in a library's government

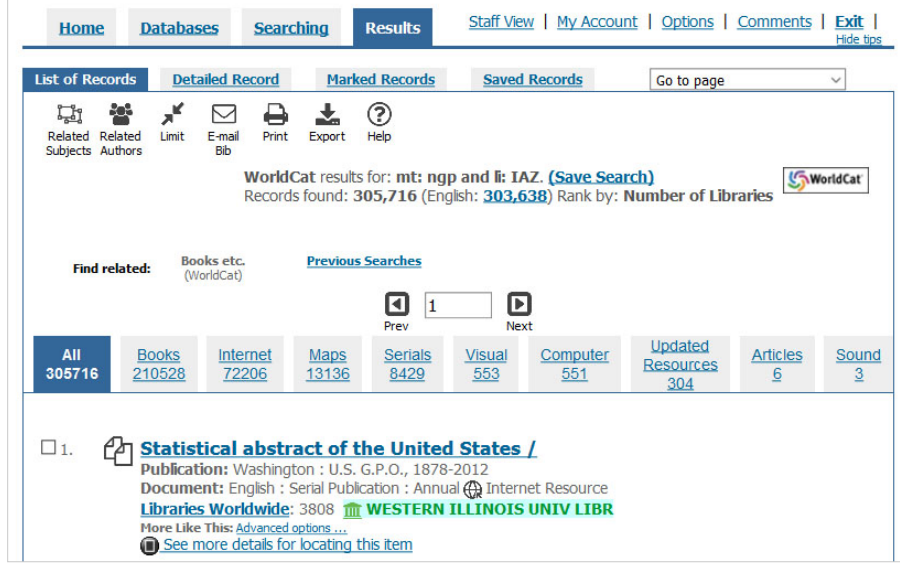

Figure 2. Image of the results of the advanced search in WorldCat for federal government publications in a library shown in figure 1.

publications collection, repeat the search, adding a second material type "mic," which is the code for any type of microform publication; remember to specify material type with the pull-down menu. If a library collects government publications from other countries, it might be necessary to limit the search by adding keywords: "United States" or "U.S.” or "US.” Limiting by country of publication is easier in the Expert Search mode of WorldCat.

\section{Using WorldCat Expert Search}

The expert search system in WorldCat can also be used to perform the same search for government publications. For example, the search below finds national government publications (ngp) in the Western Illinois University Libraries (IAZ) that were published in the United States:

mt: ngp and li: IAZ and $\mathrm{cp}=$ United States

$\mathrm{mt}$ : is the label for material type (ngp); li: is the label for owning library (IAZ is the code for the Western Illinois University Libraries; enter your library's code here); and $\mathrm{cp}=$ is the label for a phrase search for the country or state of publication. Information on the Country of Publication can be found in OCLC's Input Standards for Fixed-Field Elements and 006: Ctry: Country of Publication and the Library of Congress' MARC Code list for Countries. ${ }^{4}$ Limiting by country of publication is especially useful if a library collects foreign government publications. Owning library codes can be found by searching the Directory of OCLC Members. ${ }^{5}$ Advanced searches could be performed to see materials on a topic that are available in other libraries, such as the libraries of academic peer institutions or other depositories in a region. If another library in an area has more government publications on a given topic, users could be referred to that library. 


\section{Analyzing a Collection's Age and Subject Coverage}

To obtain a more precise breakdown of a collection's age, it is possible to perform an advanced or expert search and enter date ranges in the Limit to: Year box. For example, the WIU Libraries have 23 federal government publications published between 1793 and 1849, 490 federal government publications published between 1850 and 1899, 10,101 federal government publications published between 1900 and 1949, 198,176 federal government publications published between 1950 and 1999, and 96,539 federal government publications published between 2000 and 2019.

This analysis can be extended further by entering subject terms (e.g., agriculture, wildlife, health, etc.) in one of the advanced search boxes and choosing Subject in the pull-down. This will give the number of government publications in a collection that might be of interest to students, faculty and staff in a particular field or department. This data could be useful for academic department accreditation reports. Combining a subject, material type and date into a search can also be used to find publications on a particular topic from a particular time period, such as the government publications in the library on "war" that were published between 1941 and 1945. This information was used to find materials for a series of D-Day displays in the WIU Library. The displays included two government publications on identifying foreign and U.S. armored vehicles from the 1940s that had been received as gifts and added to the main collection. Limiting a search by age could be useful in weeding when a library only wants to keep the most recent information on a topic. It could also be used to ensure that the library is not discarding materials that are less than 5 years old.

\section{Conclusion}

Librarians can evaluate their government publication collections by searching for government publications as a material type in OCLC's WorldCat. The search can be refined by subject and date to develop reports about government information on a particular subject, or identify materials on a theme that might be of interest in displays. Using WorldCat to evaluate government information collections is especially useful in libraries where documents are cataloged and shelved with the main library collection. Unfortunately, this type of search only works for government document collections that have been cataloged. However, librarians working in libraries with uncataloged government publications could use these techniques to collect statistics on the government publication holdings of peer institutions to help justify cataloging their local collections. Cataloging government publications will improve access and services for local users, and increase access for the wider user community.

Linda Zellmer (Ir-zellmer@wiu.edu), Government Information \& Data Services Librarian, Western Illinois University

\section{References}

1. OCLC, "Bibliographic Formats and Standards," Input Standards for Fixed-Field Elements and 006: GPub: Government Publication, 4th edition (Dublin, OH: OCLC, 2018), https://tinyurl.com/y4jw6vnm.

2. OCLC, Input Standards for Fixed-Field Elements and 006: GPub: Government Publication.

3. "Material Types," OCLC, last modified August 28, 2018, https://tinyurl.com/y23p86tx.

4. OCLC, "Bibliographic Formats and Standards"; "MARC Code List for Countries," Library of Congress, last modified April 4, 2008, https://tinyurl.com/7llhdx3.

5. "Directory of OCLC Members," OCLC, https://tinyurl .com/y3fs5jt6. 